\title{
Are There Rational Bubbles in the US Stock Market? Overview and a New Test
}

A. (Tassos) G. Malliaris

Loyola University Chicago, tmallia@luc.edu

Ramaprasad Bhar

The University of New South Wales

Follow this and additional works at: https://ecommons.luc.edu/business_facpubs

Part of the Business Commons, and the Economics Commons

\section{Author Manuscript}

This is a pre-publication author manuscript of the final, published article.

\section{Recommended Citation}

Bhar, Ramaprasad and Malliaris, A. (Tassos) G., Are There Rational Bubbles in the US Stock Market? Overview and a New Test. ASSET PRICE BUBBLES: IMPLICATIONS FOR MONETARY AND REGULATORY POLICY, ELSEVIER SCIENCE, George Kaufman, ed., pp. 125-144, Elsevier Science, 2001. Available at SSRN: https://ssrn.com/abstract $=1084582$

This Book Chapter is brought to you for free and open access by the Faculty Publications and Other Works by Department at Loyola eCommons. It has been accepted for inclusion in School of Business: Faculty Publications and Other Works by an authorized administrator of Loyola eCommons. For more information, please contact ecommons@luc.edu.

\section{cc) (†) $\ominus$}

This work is licensed under a Creative Commons Attribution-Noncommercial-No Derivative Works 3.0 License. (c) Elsevier Science, 2001. 


\title{
ARE THERE RATIONAL BUBBLES IN THE US STOCK MARKET? OVERVIEW AND A NEW TEST
}

\author{
Ramaprasad Bhar \\ School of Banking and Finance \\ The University of New South Wales \\ Sydney 2052, AUSTRALIA \\ E-mail: R.Bhar@unsw.edu.au \\ A. G. Malliaris \\ Department of Economics \\ Loyola University of Chicago \\ 820 N. Michigan Avenue \\ Chicago, Illinois 60611 \\ E-mail: tmallia@luc.edu
}

\begin{abstract}
A speculative bubble is usually defined as the difference between the market value of a security and its fundamental value. Although there are several important theoretical issues surrounding the topic of asset bubbles, the existence of bubbles is inherently an empirical issue that has not been settled yet. This paper reviews several important tests and offers one more methodology that improves upon the existing ones. The new test is applied to the annual US stock market data spanning over a century and at the monthly frequency covering the post-war period. Although we find evidence of stock price bubble in both cases, the post-war period exhibit only positive component whereas the annual data exhibit some episode of negative bubble.
\end{abstract}

Journal of Economic Literature Classification System: C1, C4, G1, E2

Key words: Stock Market, Asset Bubbles, Testing for Market Overvaluation, Fundamental Valuation. 


\section{INTRODUCTION}

During the past 30 years, theoretical models and empirical testing in asset pricing have been motivated by market efficiency. This theory claims that the price of an asset today reflects correctly the future random payoffs of this asset conditioned on today's information and appropriately discounted by a stochastic factor. The opportunity to make a riskless profit using arbitrage strategies ensures that markets are efficient. Campbell (2000) articulates this paradigm in detail.

Many economists accept market efficiency as the well-established paradigm of financial economics but also acknowledge that asset prices are too volatile. For example, NASDAQ, from its peak on March 10, 2000 when it stood at 5048.62 to its low of 1638.80 on April 4, 2001, it declined by $67.5 \%$. Is this significant decline due to substantial revisions of the expected payoffs and/or changes in the discount factor?

This paper considers the rational bubble approach as an alternative to the present value model of market efficiency. We make a clear distinction between the speculative past famous bubble episodes that involved specific assets, such as tulips, John Law's Mississippi Bubble or even the stock market of the 1920s, all of which ended in a crash and what the current literature defines as "rational bubbles". Section 2 reviews the general ideas of rational bubbles and section 3 identifies two key statistical tests proposed by economists. In section 4 we offer a modification of the existing tests and apply it to the US stock market. We find evidence of rational bubbles in annual data spanning over a century as well as in monthly data covering the post-war period. In sections 5 and 6 we elaborate in detail our methodological procedures to test for bubbles and compare this 
with a no-bubble solution. Our main findings and the conclusions are given in the last two sections.

\section{SPECULATIVE BUBBLES}

Economists have long conjectured that movements in stock prices may involve speculative bubbles, as trading is often said to generate over-priced markets. Some economists, however, believe that stock price fluctuations reflect changes in the values of the underlying market fundamentals. The standard definition of fundamental value is the summed discounted value of all future cash flows. The difference, if any, between the market value of the security and its fundamental value is termed a speculative bubble. Yet confusion persists about what factors generate bubbles. Fads and irrationality have always figured prominently, and the hypothesis that these factors are important has gained some empirical support from the literature on asset price volatility. Another bubble-producing factor is the structure of information in the market. In a partialequilibrium setting, Allen and Gorton (1988) showed that rational bubbles can exist with a finite number of agents who had asymmetric information.

The existence of bubbles is inherently an empirical issue that has not been settled yet. A number of studies such as Blanchard and Watson (1982) and West (1988) have argued that dividend and stock price data are not consistent with the "market fundamentals" hypothesis, in which prices are given by the present discounted values of expected dividends. These results have often been construed as evidence for the existence of bubbles or fads.

According to Shiller (1981), and LeRoy and Porter (1981) the variability of stock price movements is too large to be explained by the present value of future earnings. 
Over the past century US stock prices are five to thirteen times more volatile than can be justified by new information about future dividends. Campbell and Shiller (1988a, b) and West $(1987,1988)$ remove the assumption of constant discount rate. But a variable discount rate provides only marginal support in explaining stock price volatility. They reject the null hypothesis of no bubbles. See also Rappoport and White $(1993,1994)$.

A major problem with such arguments is that evidence for bubbles can be reinterpreted in terms of market fundamentals that are unobserved by the econometricians (Flood and Garber (1980); Hamilton and Whiteman (1985); Hamilton (1986)). Diba and Grossman (1984, 1988a, 1988b), have recommended the alternative strategy of testing for rational bubbles by investigating the stationarity properties of asset prices and observable fundamentals.

In essence, the argument for equities is that if stock prices are not more explosive than dividends, then it can be concluded that rational bubbles are not present, since they would generate an explosive component in stock prices. Using unit-root tests, autocorrelation patterns, and cointegration tests to implement this procedure, several authors reach the conclusion that stock prices do not contain explosive rational bubbles (see Dezhbakhsh and Demirgue-Kunt (1990)).

Evans (1991) criticizes tests for bubbles based on an investigation of the stationarity properties of stock prices and dividends. By Monte-Carlo simulations he demonstrates that an important class of rational bubbles cannot be detected by these tests even though the bubbles are explosive.

Froot and Obstfeld (1991), introduce the concept of intrinsic bubble which they define as exclusively dependent on market fundamentals and not on extraneous events. 
Assuming that a stock price should go to zero as dividends go to zero, they derive a bubble solution composed of stable and unstable components. This bubble is unstable and implies an explosive price-dividend ratio. They find significant evidence of such a bubble and demonstrate that incorporating an intrinsic bubble into the simple presentvalue model helps account for the long-run variability of the US stock data. Furthermore, as their bubble is a deterministic function of dividends, once the bubble gets started, it will never burst as long as dividends remain positive. In practice, tests for intrinsic bubbles are very easily implemented only when dividends are assumed to follow a very simple process, for example, a geometric random walk. When a more general dynamic specification, such as ARIMA (p, 1, q) process is introduced for dividends, the test procedure for intrinsic bubbles becomes virtually intractable.

Using a stochastic dividend-growth model, Ikeda and Shibata (1992) specify the stock price as a function of dividends (i.e. market fundamentals) as well as of time. The resulting bubble solution will bridge a gap between time-driven bubbles (Flood and Garber (1980)) and bubbles exclusively depending on fundamentals (Froot and Obstfeld (1991)). Depending on a parameter that decides relative degrees of fundamental dependency and time dependency, the bubble solution obtained exhibits various dynamic properties that cannot be derived by combining linearly the two special solutions.

Wu (1997) examines a stochastic bubble, able to burst and restart continuously. The specification is parsimonious and allows easy estimation. The model fits the data reasonably well, especially during several bull and bear markets in this century. Much of the deviation of US stock prices from the simple present-value model can be explained by such rational stochastic bubbles. 
Miller and Weller (1990), and Buiter and Pesenti (1991) examine the effects of fundamental-dependents bubbles on exchange rate dynamics, using log linear models in which the consideration of free-disposal or price-sensitivity constraint is not required.

A rational speculative bubble is nonnegative by definition: it represents what an investor might be willing to pay to buy a stock forever stripped of its dividends. As soon as either dividends or discount rates depend on the presence or absence of a bubble, however, the fundamental is affected by the presence of a bubble. For instance, the existence of a bubble may lead to an increase in interest rates which so depresses the fundamental that the sum of the positive bubble and the bubbly fundamental falls short of the nonbubbly fundamental. Hence, a positive rational bubble may in fact decrease the overall price of a stock, contrary to what is commonly believed. Empirical tests of this hypothesis are provided, for example by Weil (1990).

Most of the references above address issues of rational bubbles either theoretically or in the context of a mature economy. To complete this rapid bibliographical review we need to mention two additional trends in this literature. First several studies have tested for the existence of bubbles in emerging markets. For example, Richards (1996) claims that emerging markets have not consistently been subject to fads or bubbles. Chan and coauthors (1998) test for rational bubbles in Asian stock markets and Chen (1999) specializes his search for bubbles in the Hong Kong market. Sarno and Taylor (1999) find evidence of bubbles in all East Asian economies. Significant increases in crossmarkets linkages after a shock have now become a topic of important research under the term "contagion". Several important papers collected in Claessens and Forbes (2001) discuss both methodological issues and case studies of contagion. 
Beyond the existence or not of bubbles, economists have also studied in detail the implications of a stock market bubble to the economy at large. Biswanger (1999) offers a comprehensive review of these issues and Chirinko and Schaller (1996) argue that bubbles existed in the US stock market but real investment decisions were based on fundamentals.

\section{REVIEW OF TWO KEY EMPIRICAL PAPERS}

To motivate our methodological contribution we review two influential papers.

\subsection{Ikeda and Shibata (1992)}

Using a stochastic dividend-growth model, the paper provides a general analysis of fundamental-dependent bubbles in stock prices. Given that dividends follow a continuous Markov process, a stock price is specified as a function of dividends as well as of time. The authors derive a partial differential equation with respect to this price function from an arbitrage equation. Provided that a free-disposal condition is satisfied, a fundamental price process is defined as the forward-looking particular solution of this equation and a price bubble as the general solution of the corresponding homogeneous equation.

Lets consider a stock share which yields dividends $\mathrm{D}(\mathrm{t})$ at time $\mathrm{t}$. These dividends follow a geometric Brownian motion with positive drift:

$$
d D(t)=g D(t) d t+o D(t) d z(t), D(0)=D_{0}, g-o^{2} / 2>0, o>0
$$

Constant g and $\sigma$ are, respectively, the expected value and the standard deviation of the instantaneous rate of dividend growth. $\mathrm{dz}$ is an independent increment of a standard Wiener process, $\mathrm{z}$, with the initial condition $\mathrm{z}(0)=0$. Since $\ln \mathrm{D}$ follows a normal distribution, the time series of dividend payments have a positive trend. 
Stochastic dividend-payment process (1) is the only source of randomness. Supposing risk neutrality of investors and free disposability of the stock, we assume that the cum-dividend stock price is determined by the following two conditions:

$\mathrm{E}\left[\mathrm{dP}(\mathrm{t}) \mid \Omega_{\mathrm{t}}\right] / \mathrm{dt}+\mathrm{D}(\mathrm{t})=\mathrm{rP}(\mathrm{t})$

$\mathrm{P}(\mathrm{t}) \geq 0$, with $\mathrm{r}>0 \forall \mathrm{t} \in[0, \infty]$ w.p.1,

where $\mathrm{E}\left[\cdot \mid \Omega_{\mathrm{t}}\right]$ represents mathematical expectations conditional on $\Omega$, and parameter $\mathrm{r}$ denotes the riskless interest rate which is assumed to be constant.

The rational expectations stochastic process of the stock price is obtained then by solving nonhomogeneous partial differential equation (2), subject to the dividend payment process (1) and the price positivity condition (3).

The author finds that the fundamentals dependency stabilizes bubble dynamics and that stock prices with fundamentals-dependent bubbles can be less volatile than fundamentals. Furthermore, fundamentals-dependent bubbles exhibit various transition patterns, such as nonmonotonic movements and monotonic shrinkage in magnitude and volatility.

\section{$3.2 \mathrm{Wu}(1997)$}

The paper estimates a rational stochastic bubble using the Kalman filtering technique. The bubble grows at the discount rate in expectation and it can collapse and restart continuously, allowing for the possibility of a negative bubble. The log dividends follow a general ARIMA (p, 1, q) process. The model for stock prices with the bubble component, the dividend process and the bubble process are expressed in the state-space form with the bubble being treated as an unobserved state vector. The model parameters 
are estimated by the method of maximum likelihood and obtain optimal estimates of stochastic bubbles through the Kalman filter.

Lets consider the standard linear rational expectations model of stock price determination:

$\left[\mathrm{E}_{\mathrm{t}}\left(\mathrm{P}_{\mathrm{t}+1}+\mathrm{D}_{\mathrm{t}}\right)-\mathrm{P}_{\mathrm{t}}\right] / \mathrm{P}_{\mathrm{t}}=\mathrm{r}$,

where $\mathrm{p}=$ real stock price at time $\mathrm{t}$

$\mathrm{D}=$ the real dividend at time $\mathrm{t}$

$\mathrm{E}=$ the mathematical expectation conditional on information available at time $\mathrm{t}$ $r=$ the required real rate of return, $r>0$.

The log-linear approximation of (6) can be written as follows:

$\mathrm{q}=\mathrm{k}+\psi \mathrm{E}_{\mathrm{t}} \mathrm{p}_{\mathrm{t}+1}+(1-\psi) \mathrm{d}_{\mathrm{t}}-\mathrm{p}_{\mathrm{t}}$

where $\mathrm{q}=$ required $\log$ gross return rate

$\Psi=$ average ratio of the stock price to the sum of the stock price and the dividend $\mathrm{k}=-\ln (\Psi)-(1-\Psi) \ln (1 / \Psi-1)$

$\mathrm{p}=\ln (\mathrm{P})$

$d=\ln (D)$.

The general solution to (7) is given by:

$\mathrm{p}_{\mathrm{t}}=(\mathrm{k}-\mathrm{q}) /(1-\psi)+(1-\psi) \sum_{\mathrm{i}=0}^{\infty} \psi^{\mathrm{i}} \mathrm{E}_{\mathrm{t}}\left(\mathrm{d}_{\mathrm{t}+\mathrm{i}}\right)+\mathrm{b}_{\mathrm{t}}=\mathrm{p}_{\mathrm{t}}^{\mathrm{f}}+\mathrm{b}_{\mathrm{t}}$

where $b_{t}$ satisfies the following homogeneous difference equation:

$\mathrm{E}_{\mathrm{t}}\left(\mathrm{b}_{\mathrm{t}+\mathrm{i}}\right)=(1 / \psi)^{\mathrm{i}} \mathrm{b}_{\mathrm{t}}$.

In equation (5), the no-bubble solution $\mathrm{p}$ is exclusively determined by dividends, while b can be driven by events extraneous to the market and is referred to as a rational 
speculative bubble. After defining the stock price equation, the parametric bubble process and the dividend process in a state-space form, the bubble is treated as an unobserved state vector, which can be estimated by the Kalman filtering technique.

The author finds statistically significant estimate of the innovation variance for the bubble process. During the 1960s bull market the bubble accounts for between $40 \%$ to $50 \%$ of the actual stock prices. Negative bubbles are found during the 1919-1921 bear market, in which the bubble explains between $20 \%$ to $30 \%$ of the decline in stock prices.

\section{OUR CONTRIBUTION}

The purpose of our study is to search empirically for bubbles in national stock markets using state-of-the-art methodology such as Wu $(1995,1997)$ with emphasis on the U.S., over different sample period and different data frequency. We analyze the market at the monthly frequency over the post-war period as opposed to Wu (1997), which concentrates on only the annual data series dating back to 1871 . The monthly returns data of the S\&P 500 ranges from January 1951 to December 1998, that is, 576 observations. All data are converted to real values using the corresponding CPI measures and Global Financial Data provided the data. In order to establish the soundness of our methodology we attempted to reproduce the results from Wu (1997) using annual U.S. data (also obtained from Global Financial Data) covering the period 1871 - 1998.

Although we employ the unobserved component modeling approach similar to $\mathrm{Wu}$ (1997), our implementations of the state space form (or the Dynamic Linear Model, DLM, (Shumway and Stoffer (2000), p. 306) is quite different from that of Wu. We treat both the dividend process and the bubble process as part of the unobserved components, that is the state vector. The state equations also include their own system error, which are 
assumed uncorrelated. The measurement vector in this case contains the price and the realized dividend without any measurement errors. The advantage of this way modeling is that the comparison with the no bubble solution becomes much more straightforward. Wu (1997) had to resort to alternative way (GMM) of estimating the no bubble solution and the model adequacy tests are not performed there. Besides, the precise moment conditions used in the GMM estimation are not reported there. On the other hand, in our approach we are able to subject both the bubble and the no bubble solutions to a battery of diagnostics test applicable to state space systems. In the following sections we describe in detail the mathematical structures of our models and the estimation strategies.

\section{DYNAMIC LINEAR MODELS FOR BUBBLE SOLUTIONS}

Our starting point in this approach are the equations (6) and (7) described earlier. As our preliminary investigations reveal that both the log real price and log real dividend series are non-stationary, we choose to work with the first differenced series. Thus, the equation (8) becomes,

$$
\Delta \mathrm{p}_{\mathrm{t}}=\Delta \mathrm{p}_{\mathrm{t}}^{\mathrm{f}}+\Delta \mathrm{b}_{\mathrm{t}}
$$

where, $\Delta \mathrm{p}_{\mathrm{t}}^{\mathrm{f}} \equiv(1-\psi) \sum_{\mathrm{i}=0}^{\infty} \psi^{\mathrm{i}} \mathrm{E}_{\mathrm{t}}\left(\mathrm{d}_{\mathrm{t}+\mathrm{i}}\right)-(1-\psi) \sum_{\mathrm{i}=0}^{\infty} \psi^{\mathrm{i}} \mathrm{E}_{\mathrm{t}-1}\left(\mathrm{~d}_{\mathrm{t}-1+\mathrm{i}}\right)$. Assuming the following parametric representation of equation (9),

$$
\begin{aligned}
& \mathrm{b}_{\mathrm{t}+1}=\frac{1}{\psi} \mathrm{b}_{\mathrm{t}}+\varepsilon_{\eta}, \varepsilon_{\eta} \square \mathrm{N}\left(0, \sigma_{\eta}^{2}\right), \\
& \Delta \mathrm{b}_{\mathrm{t}}=\frac{1}{\psi}\left(\mathrm{b}_{\mathrm{t}}-\mathrm{b}_{\mathrm{t}-1}\right) .
\end{aligned}
$$

In order to express the fundamental component of the price, $\Delta \mathrm{p}_{\mathrm{t}}^{\mathrm{f}}$, in term of the dividend process, we fit an appropriate AR model of sufficient order so that the 
information criterion AIC is minimized. We find that for the annual data an AR(2) model is sufficient whereas for the monthly data we need an $\mathrm{AR}(3)$ model. The infinite sums in the expression for $\Delta \mathrm{p}_{\mathrm{t}}^{\mathrm{f}}$ may be expressed in terms of the parameters of the dividend process once we note the following conditions:

- The differenced log real dividend series is stationary, therefore the infinite sum converges,

- Any finite order AR process can be expressed in companion form (VAR of order 1) by using extended state variables, that is, suitable lags of the original variables as in Campbell, Lo and MacKinlay (1997, p. 280),

- Using demeaned variables the VAR(1) process can be easily used for multi-period ahead forecast.

Assuming the demeaned log real dividend process has the following AR(3) representation,

$\Delta \mathrm{d}_{\mathrm{t}}=\phi_{1} \Delta \mathrm{d}_{\mathrm{t}-1}+\phi_{2} \Delta \mathrm{d}_{\mathrm{t}-2}+\phi_{3} \Delta \mathrm{d}_{\mathrm{t}-3}+\varepsilon_{\delta}, \varepsilon_{\delta} \square \mathrm{N}\left(0, \sigma_{\delta}^{2}\right)$,

the companion form may be written as,

$\left[\begin{array}{c}\Delta \mathrm{d}_{\mathrm{t}} \\ \Delta \mathrm{d}_{\mathrm{t}-1} \\ \Delta \mathrm{d}_{\mathrm{t}-2}\end{array}\right]=\left[\begin{array}{ccc}\phi_{1} & \phi_{2} & \phi_{3} \\ 1 & 0 & 0 \\ 0 & 1 & 0\end{array}\right]\left[\begin{array}{c}\Delta \mathrm{d}_{\mathrm{t}-1} \\ \Delta \mathrm{d}_{\mathrm{t}-2} \\ \Delta \mathrm{d}_{\mathrm{t}-3}\end{array}\right]+\left[\begin{array}{c}\varepsilon_{\delta} \\ 0 \\ 0\end{array}\right]$, or

$\mathrm{X}_{\mathrm{t}}=\Phi \mathrm{X}_{\mathrm{t}-1}+\Xi_{\mathrm{t}}$,

where, the definitions of $X_{t}, \Phi$, and $\Xi_{t}$ are obvious from comparison of equations (12) and (13). Following Campbell, Lo and MacKinlay (1997, p. 280), $\Delta \mathrm{p}_{\mathrm{t}}^{\mathrm{f}}$ may be expressed as, with I being the identity matrix of the same dimension as $\Phi$ 
$\Delta \mathrm{p}_{\mathrm{t}}^{\mathrm{f}}=\Delta \mathrm{d}_{\mathrm{t}}+\psi \Phi(\mathrm{I}-\psi \Phi)^{-1} \Delta \mathrm{X}_{\mathrm{t}}$

We can now express equation (8) in terms of fundamental component and the bubble component,

$\Delta \mathrm{p}_{\mathrm{t}}=\Delta \mathrm{d}_{\mathrm{t}}+\mathrm{e}^{\prime} \psi \Phi(\mathrm{I}-\psi \Phi)^{-1} \Delta \mathrm{X}_{\mathrm{t}}+\Delta \mathrm{b}_{\mathrm{t}}$

where $\mathrm{e}^{\prime} \equiv\left[\begin{array}{lll}1 & 0 & 0\end{array}\right]$

The equation (15) represents the measurement equation of the DLM and we need to suitably define the state equation for the model. An examination of the equation (10) and (12) suggests that the following state equation adequately represent the dynamics of the dividend and the bubble process:

$$
\begin{aligned}
& {\left[\begin{array}{c}
\Delta \mathrm{d}_{\mathrm{t}} \\
\Delta \mathrm{d}_{\mathrm{t}-1} \\
\Delta \mathrm{d}_{\mathrm{t}-2} \\
\Delta \mathrm{d}_{\mathrm{t}-3} \\
\mathrm{~b}_{\mathrm{t}} \\
\mathrm{b}_{\mathrm{t}-1}
\end{array}\right]=\left[\begin{array}{cccccc}
\phi_{1} & \phi_{2} & \phi_{3} & 0 & 0 & 0 \\
1 & 0 & 0 & 0 & 0 & 0 \\
0 & 1 & 0 & 0 & 0 & 0 \\
0 & 0 & 1 & 0 & 0 & 0 \\
0 & 0 & 0 & 0 & \frac{1}{\psi} & 0 \\
0 & 0 & 0 & 0 & 1 & 0
\end{array}\right]\left[\begin{array}{c}
\Delta \mathrm{d}_{\mathrm{t}-1} \\
\Delta \mathrm{d}_{\mathrm{t}-2} \\
\Delta \mathrm{d}_{\mathrm{t}-3} \\
\Delta \mathrm{d}_{\mathrm{t}-4} \\
\mathrm{~b}_{\mathrm{t}-1} \\
\mathrm{~b}_{\mathrm{t}-2}
\end{array}\right]+\left[\begin{array}{cc}
\varepsilon_{\delta} & 0 \\
0 & 0 \\
0 & 0 \\
0 & 0 \\
0 & \varepsilon_{\eta} \\
0 & 0
\end{array}\right],} \\
& \left(\begin{array}{c}
\varepsilon_{\delta} \\
\varepsilon_{\eta}
\end{array}\right) \square \mathrm{N}\left(\left[\begin{array}{c}
0 \\
0
\end{array}\right],\left[\begin{array}{cc}
\sigma_{\delta}^{2} & 0 \\
0 & \sigma_{\eta}^{2}
\end{array}\right]\right) .
\end{aligned}
$$

We are in a position now to define the measurement equation of the DLM in term of the state vector in equation (16). This is achieved by examining equation (15) and defining a row vector, $\mathrm{M} \equiv \mathrm{e}^{\prime} \psi \Phi(\mathrm{I}-\psi \Phi)^{-1}=\left[\mathrm{m}_{1}, \mathrm{~m}_{2}, \mathrm{~m}_{3}\right]$, as follows:

$$
\Delta \mathrm{p}_{\mathrm{t}}=\Delta \mathrm{d}_{\mathrm{t}}+\left[\mathrm{m}_{1}, \mathrm{~m}_{2}, \mathrm{~m}_{3}\right]\left[\begin{array}{c}
\Delta \mathrm{d}_{\mathrm{t}}-\Delta \mathrm{d}_{\mathrm{t}-1} \\
\Delta \mathrm{d}_{\mathrm{t}-1}-\Delta \mathrm{d}_{\mathrm{t}-2} \\
\Delta \mathrm{d}_{\mathrm{t}-2}-\Delta \mathrm{d}_{\mathrm{t}-3}
\end{array}\right]+\Delta \mathrm{b}_{\mathrm{t}}, \text { or }
$$




$$
\left[\begin{array}{c}
\Delta \mathrm{p}_{\mathrm{t}} \\
\Delta \mathrm{d}_{\mathrm{t}}
\end{array}\right]=\left[\begin{array}{cccccc}
\left(1+\mathrm{m}_{1}\right) & \left(\mathrm{m}_{2}-\mathrm{m}_{1}\right) & \left(\mathrm{m}_{3}-\mathrm{m}_{2}\right) & -\mathrm{m}_{3} & 1 & -1 \\
1 & 0 & 0 & 0 & 0 & 0
\end{array}\right]\left[\begin{array}{c}
\Delta \mathrm{d}_{\mathrm{t}} \\
\Delta \mathrm{d}_{\mathrm{t}-1} \\
\Delta \mathrm{d}_{\mathrm{t}-2} \\
\Delta \mathrm{d}_{\mathrm{t}-3} \\
\mathrm{~b}_{\mathrm{t}} \\
\mathrm{b}_{\mathrm{t}-1}
\end{array}\right] .
$$

The equation (17) determines the measurement equation of the DLM without any measurement error. In other words, the evolution of the state vector in equation (16) results in the measurement of the measurement vector through equation (17).

We have now set up the DLM for the bubble solution for the monthly data given by equations (16) and (17). For the annual data since the dividend process is an AR(2), these equations need to be appropriately redefined. The parameters of the models embedded in these equations and the filtered and the smoothed estimates of the bubble series are to be estimated from the observed price and the dividend series. The details of the estimation procedure are described in the appendix A. In the next subsection we proceed to set up the DLMs for the no-bubble solutions.

\section{DYNAMIC LINEAR MODELS FOR NO-BUBBLE SOLUTIONS}

In order to compare the performance of the bubble solution discussed in the previous subsection we develop the DLM for a no-bubble solution. We maintain the same framework so that comparison is more meaningful. This is opposed to the approach taken in $\mathrm{Wu}$ (1997) where the no-bubble solution was estimated in the GMM framework. We also note that the model should account for the correlations in the variance of the stock return series. This is done by incorporating the $\operatorname{GARCH}(1,1)$ effect in the price equation (8) without the bubble component. In this context we adopt the methodology of Harvey, Ruiz 
and Sentana (1992) and follow Kim and Nelson (1999, page 144) to suitably augment the state vector of the DLM.

For the monthly data set the state equation (16) becomes,

$$
\begin{aligned}
& {\left[\begin{array}{c}
\Delta \mathrm{d}_{\mathrm{t}} \\
\Delta \mathrm{d}_{\mathrm{t}-1} \\
\Delta \mathrm{d}_{\mathrm{t}-2} \\
\Delta \mathrm{d}_{\mathrm{t}-3} \\
\varepsilon_{\mathrm{p}, \mathrm{t}}
\end{array}\right]=\left[\begin{array}{ccccc}
\phi_{1} & \phi_{2} & \phi_{3} & 0 & 0 \\
1 & 0 & 0 & 0 & 0 \\
0 & 1 & 0 & 0 & 0 \\
0 & 0 & 1 & 0 & 0 \\
0 & 0 & 0 & 0 & 0
\end{array}\right]\left[\begin{array}{c}
\Delta \mathrm{d}_{\mathrm{t}-1} \\
\Delta \mathrm{d}_{\mathrm{t}-2} \\
\Delta \mathrm{d}_{\mathrm{t}-3} \\
\Delta \mathrm{d}_{\mathrm{t}-4} \\
\varepsilon_{\mathrm{p}, \mathrm{t}-1}
\end{array}\right]+\left[\begin{array}{cc}
\varepsilon_{\delta} & 0 \\
0 & 0 \\
0 & 0 \\
0 & 0 \\
0 & \varepsilon_{\mathrm{p}, \mathrm{t}}
\end{array}\right],} \\
& \left(\begin{array}{c}
\varepsilon_{\delta} \\
\varepsilon_{\mathrm{p}, \mathrm{t}} \mid \omega_{\mathrm{t}-1}
\end{array}\right) \square \mathrm{N}\left(\left[\begin{array}{l}
0 \\
0
\end{array}\right],\left[\begin{array}{cc}
\sigma_{\delta}^{2} & 0 \\
0 & \mathrm{~h}_{\mathrm{t}}
\end{array}\right]\right), \mathrm{h}_{\mathrm{t}}=\alpha_{0}+\alpha_{1} \varepsilon_{\mathrm{p}, \mathrm{t}-1}^{2}+\beta_{1} \mathrm{~h}_{\mathrm{t}-1},
\end{aligned}
$$

and $\omega_{t-1}$ is the information set at time $t-1$. The corresponding measurement equation becomes,

$$
\left[\begin{array}{c}
\Delta \mathrm{p}_{\mathrm{t}} \\
\Delta \mathrm{d}_{\mathrm{t}}
\end{array}\right]=\left[\begin{array}{ccccc}
\left(1+\mathrm{m}_{1}\right) & \left(\mathrm{m}_{2}-\mathrm{m}_{1}\right) & \left(\mathrm{m}_{3}-\mathrm{m}_{2}\right) & -\mathrm{m}_{3} & 1 \\
1 & 0 & 0 & 0 & 0
\end{array}\right]\left[\begin{array}{c}
\Delta \mathrm{d}_{\mathrm{t}} \\
\Delta \mathrm{d}_{\mathrm{t}-1} \\
\Delta \mathrm{d}_{\mathrm{t}-2} \\
\Delta \mathrm{d}_{\mathrm{t}-3} \\
\varepsilon_{\mathrm{p}, \mathrm{t}}
\end{array}\right] .
$$

For the annual data again with an AR(2) dividend process, the no-bubble DLM will have to be appropriately defined by modifying the equations (18) and (19). In the no-bubble solutions the parameters to be estimated are those of the dividend process and the GARCH(1,1) coefficients.

\section{RESULTS AND DISCUSSIONS}

First we discuss the estimations results of the dynamic linear model with the bubble solution for the annual U.S. data series. In Table 1 we find all the parameter estimates are statistically significant. The significance of the parameter, $\sigma_{\eta}$, implies highly variable 
bubble component of the price through out the period 1871 to 1998 . The parameters describing the real dividend process are very close to the univariate estimation (not included) results of the dividend series. Besides, the discount parameter, $\psi$, is close to its sample value.

In Table 2 we present the estimates of the no-bubble solution with a GARCH $(1,1)$ error structure for the price equation for the same U.S. annual data. Here also, most of the parameters are statistically significant. The significance of the GARCH parameter, $\beta_{1}$, implies persistence in the residual volatility. This model is used to compare the results of the bubble solution. We would like to stress the fact we implemented the GARCH $(1,1)$ model also in the state space framework so that the comparison with the bubble solution would be more realistic. This is, however, not the case with $\mathrm{Wu}$ (1997), which uses the GMM methodology. This approach also allows us to check the performance of both the models by analyzing the residual diagnostics. We present these test results in Table 3 . The portmanteau tests support the whiteness of the residuals and the ARCH tests indicate no remaining heteroscedasticity in the residuals. Besides, the Kolmogorov-Smirnov tests support the normality of the residuals. These three tests overwhelmingly support the modeling approach adopted here and, therefore, the conclusions drawn are statistically meaningful.

In addition to the three tests just outlined above, we also include two additional tests particularly designed for recursive residuals produced by the dynamic linear systems developed in this study. The modified von-Neumann ratio tests against serial correlations in the residuals where as the recursive t-test is used to check for correct model specification. As the entries Table 3 suggest both the models, i.e. the dynamic linear 
models of the bubble and the no-bubble solution, both perform extremely well in respect of these two tests. There is overwhelming support for the adequacy of the models in describing the price process.

In view of the battery of tests discussed in the preceding two paragraphs we can now proceed to analyze the other observations. As discussed in Wu (1997), the rational stochastic bubble can alternate between positive and negative values. It is argued there that the securities may be overvalued when the participants are bullish and these may be undervalued when the participants are bearish. Figure 1 shows negative bubble in the very early part of the sample as well as during the early 1920s. It is obvious though that the stochastic bubbles account for a substantial percentage of the stock price in the sample. It is also interesting to note that in spite of the drop in the bubble percentage during the oil shock of the1970's and the stock market crash of 1987 there has been a upward trend of the bubble percentage through out the later part of the sample period considered. This particular feature is most clearly visible in the lower panel of Figure 1, which separates the stock price in the fundamental and the bubble components.

Next, we compare the performance of the bubble and the no-bubble solutions by examining the in sample fitting the stock prices. In Table 4 we display the criteria used and these are defined as,

$\operatorname{RMSE}=\frac{1}{\mathrm{~T}} \sum_{\mathrm{t}=1}^{\mathrm{T}}\left(\hat{\mathrm{p}}_{\mathrm{t}}-\mathrm{p}_{\mathrm{t}}\right)^{2}, \operatorname{MAE}=\frac{1}{\mathrm{~T}} \sum_{\mathrm{t}=1}^{\mathrm{T}}\left|\hat{\mathrm{p}}_{\mathrm{t}}-\mathrm{p}_{\mathrm{t}}\right|$,

where $\hat{p}_{t}$ is the fitted price and $T$ is the number of observations. The entries in Table 4 clearly demonstrate the superiority of the bubble solution to capture the price process over the sample period. 
We next proceed to analyze the monthly data, covering the post war period. Table 1 also presents the estimation results of the bubble solutions and it is clear that most of the parameters are statistically significant. The discount parameter, $\psi$, as before is close to the respective sample values while the significant $\sigma_{\eta}$ implies highly variable bubble components. Needless to say that the estimated parameters of the dividend processes are close to their respective univariate estimation (not reported here) results. As evident from Table 2, the significant ARCH and the GARCH parameters indicate appropriateness of the error specification for the log price difference series. There is substantial persistence in the variance process.

The residual diagnostics for the monthly data series indicate whiteness on residuals from the portmanteau test and the lack of ARCH effect in the residuals from ARCH test results. It also supports the normality of the residuals. More importantly though the tests for model adequacy are captured by the von-Neumann ratio and the recursive t-test. As pointed out in Harvey (1990, page 157) von-Neumann test provides the most appropriate basis for a general test of misspecification with recursive residuals. In this context the dynamic linear models for the bubble and the no-bubble solutions both perform extremely well.

Figure 2 plots the bubble price ratio for the monthly sample period and the substantial variation of the bubble component is clearly visible. There is no evidence of negative bubble in the sample period. The effect of the oil price shock of the 1970s is also visible. The fall in the bubble percentage during the October 1987 stock market crash is also evident. This provides the visual evidence of the collapsing and self-starting nature of the rational stochastic bubble we have attempted to capture in this study. 
In order to quantify the performance improvement of the bubble solution compared to the no-bubble case with GARCH $(1,1)$ errors we note the in sample fitting statistics, RMSE and MAE, in Table 4. The entries prove beyond doubt that the bubble solution does a credible job in terms of both metrics. For example, the bubble solution reduces the metric RMSE to $7 \%$ and the metric MAE to $52 \%$ of the no-bubble solution respectively, for the monthly data.

\section{CONCLUSION}

Economists have long conjectured that movements in stock prices may involve speculative bubbles because trading often generates over-priced markets. A speculative bubble is usually defined as the difference between the market value of a security and its fundamental value. Although there are several important theoretical issues surrounding the topic of asset bubbles, the existence of bubbles is inherently an empirical issue that has not been settled yet. This paper reviews several important tests and offers a new methodology that improves upon the existing ones. In addition, the new methodology is applied to the US stock market data over two sample periods and at two different data frequencies. The annual data spans over a century and the monthly data covers the postwar period.

We find evidence of bubbles explaining a large percentage of the observed prices in both samples. Although the rational stochastic bubble exhibit negative episode in the annual data in the early part of the century, the post-war period exhibit only positive bubble component. 
Acnowledgement: An earlier version of this paper was presented at the Western Economic Association Meetings in San Fransisco and at the Athens University of Economics and Business, Athens, Greece. The authors are very grateful to seminar participants and discussants for their valuable comments and to Professor George Kaufman for the invitation to contribute this paper to the current volume.

\section{REFERENCES}

Adler, M. and B. Dumas, 1983. International Portfolio Choice and Corporation Finance: A Synthesis, Journal of Finance 38, 925-984.

Agmon, T., 1972. The Relations Among Equity Markets: A Study of Share Price Comovements in the United States, United Kingdom, Germany and Japan, Journal of Finance 27, 839-855.

Agmon, T., 1973. Country Risk: Significance of Country Factor for Share Price Movements in the United Kingdom, Germany, and Japan, Journal of Business 46, 24-32.

Allen, F., G. Gorton, 1988. Rational Finite Bubbles, mimeo, The Wharton School, University of Pennsylvania.

Binswanger, M., 1999. Stock Markets, Speculative Bubbles and Economic Growth, Cheltenham, U.K.:Elgar Publishing.

Blanchard, O. J., M. Watson, 1982. Bubbles, Rational Expectations and Financial Markets, in P. Wachel, ed., Crises in the Economic and Financial Structure, Lexington: Lexington Books.

Campbell, J. Y. 2000. Asset Pricing at the Millennium, The Journal of Finance 55, 1515-1568.

Campbell, J. Y., R. J. Shiller, 1988a. The Dividend-Price Ratio and the Expectations of Future Dividends and Discount Factors, Review of Financial Studies 1, 195-228. Campbell, J. Y., R. J. Shiller, 1988b. Stock Prices, Earnings and Expected Dividends, Journal of Finance 43, 661-676.

Chan, K., G. McQueen., S. Thorley, 1998. Are there Rational Speculative Bubbles in 
Asian Stock Markets?, Pacific-Basin Finance Journal 6, 125-151.

Chen, J.,1999. When the Bubble Is Going to Burst, International Journal of Theoretical and Applied Finance 2, 285-92.

Chirinko, R., H. Schaller, 1996. Bubbles, Fundamentals, and Investment: A Multiple Equation Testing Strategy, Journal of Monetary Economics 38, 47-76.

Christofi, A. C., Philippatos, G. C., 1987. An Empirical Investigation of the International Arbitrage Pricing Theory, Management International Review 27, 13-22.

Claessens, S., K. Forbes, editors, 2001. International Financial Contagion, Amsterdam:

Kluwer Academic Publishers.

Dezhbakhsh, H., A. Demirguc-Kunt, 1990. On the Presence of Speculative Bubbles in Stock Prices, Journal of Financial and Quantitative Analysis 25, 101-112.

Diba, B. T., H. I. Grossman, 1984. Rational Bubbles in the Price of Gold, National Bureau of Economic Research, Working Paper No. 1300.

Diba, B. T., H. I. Grossman, 1988a. The Theory of Rational Bubbles in Stock Prices, Economic Journal 98, 746-754.

Diba, B. T., H. I. Grossman, 1988b. Explosive Rational Bubbles in Stock Prices, American Economic Review 78, 520-530.

Evans, G. E., 1991. Pitfalls in Testing for Explosive Bubbles in Asset Prices, American Economic Review 81, 922-930.

Flood, R. P., P. M. Garber, 1980. Market Fundamentals versus Price Level Bubbles: The First Tests, Journal of Political Economy 88, 745-770.

Froot, K. A., M. Obstfeld, 1991. Intrinsic Bubbles: The Case of Stock Prices, American Economic Review 81, 1189-214.

Gilles, C., S. F. LeRoy, 1992. Bubbles and Charges, International Economic Review 33, 323-339.

Granger, C.W.J., 1969, Investigating Causal Relations by Econometric Models and Cross Spectral Methods, Econometrica 37, 428-438.

Hamao, Y., R. W. Masulis, V. Ng, 1990. Correlations in Price Changes and Volatility Across International Stock markets, The Review of Financial Studies 3, 281-307. Hamilton J. D., and C. H. Whiteman, 1985. The Observable Implications of SelfFulfilling Expectations, Journal of Monetary Economics 16, 353-73. 
Hamilton, J. D., 1985. On Testing for Self-Fulfilling Speculative Price Bubbles, International Economic Review 27, 545-552.

Harvey, A. C., 1990. The Econometric Analysis of Time Series, second edition, Cambridge, Massachusetts: The MIT Press.

Harvey, Andrew., Ruiz, Esther., Sentana, Enrique, 1992. Unobserved Component Time Series Models with ARCH Disturbances, Journal of Econometrics 52, 129-157.

Ikeda, S., A. Shibata, 1992. Fundamentals-Dependent Bubbles in Stock Prices, Journal of Monetary Economics 30, 143-168.

Kim, C., Nelson, C. R., 1999. State Space Models with Regime Switching: Classical and Gibbs-Sampling Approach with Applications, Cambridge: The MIT Press.

LeRoy, S., R. D. Porter, 1981. The Present-Value Relation: Tests Based on Implied Variance Bounds, Econometrica 49, 555-74.

Lutkepohl, H., 1993. Introduction to Multiple Time Series Analysis, second edition, New York: Spinger-Verlag.

McCarthy, J., Najand, M., 1995. State Space Modelling of Linkages among International Markets, Journal of Multinational Financial Management 5, 1-9.

Pierce, d. A., L. D. Haugh, 1977. Causality in Temporal Systems: Characterizations and a Survey, Journal of Econometrics 5, 265-293.

Rappoport, P., E. N. White, 1993. Was There a Bubble in the 1929 Stock Market?, Journal of Economic History 53, 549-574.

Rappoport, P., E. N. White, 1994. The New York Stock Market in the 1920s and 1930s:

Did Stock Prices Move Together Too Much?, NBER Working Paper, No. 4627.

Sarno, L., M. Taylor, 1999. Moral Hazard, Asset Price Bubbles, Capital Flows and the East Asian Crisis: The First Test, Journal of International Money and Finance 18, 637-657.

Shiller, R. J., 1978. Rational Expectations and the Dynamic Structure of Macroeconomic Models, Journal of Monetary Economics 4, 1-44.

Shiller, R. J., 1981. Do Stock Price Move too Much to be Justified by Subsequent Changes in Dividends?, American Economic Review 71, 421-436.

Shumway, R.H., Stoffer, D. S., 2000. Time Series Analysis and Its Applications, New York: Springer. 
Tirole, J., 1982. On the Possibility of Speculation under Rational Expectations, Econometrica 50, 1163-1181.

Tirole, J., 1985. Asset Bubbles and Overlapping Generations, Econometrica 53, 1499-1528.

Weil, P., 1990. On the Possibility of Price Decreasing Bubbles, Econometrica 58, 1467-1474.

Wells, C. 1996. The Kalman Filter in Finance, Amsterdam: Kluwer Academic Publishers.

West, K. D., 1988. Bubbles, Fads, and Stock Price Volatility Tests: A Partial Evaluation,

National Bureau of Economic Research, Working Paper No. 2574.

West, K. D., 1987. A Specification Test for Speculative Bubbles, Quarterly Journal of Economics 102, 553-580.

Wu, Y., 1995. Are There Rational Bubbles in Foreign Exchange Markets?, Journal of International Money and Finance 14, 27-46.

Wu, Y., 1997. Rational Bubbles in the Stock Market: Accounting for the U.S. StockPrice Volatility, Economic Inquiry 35, 309-319.

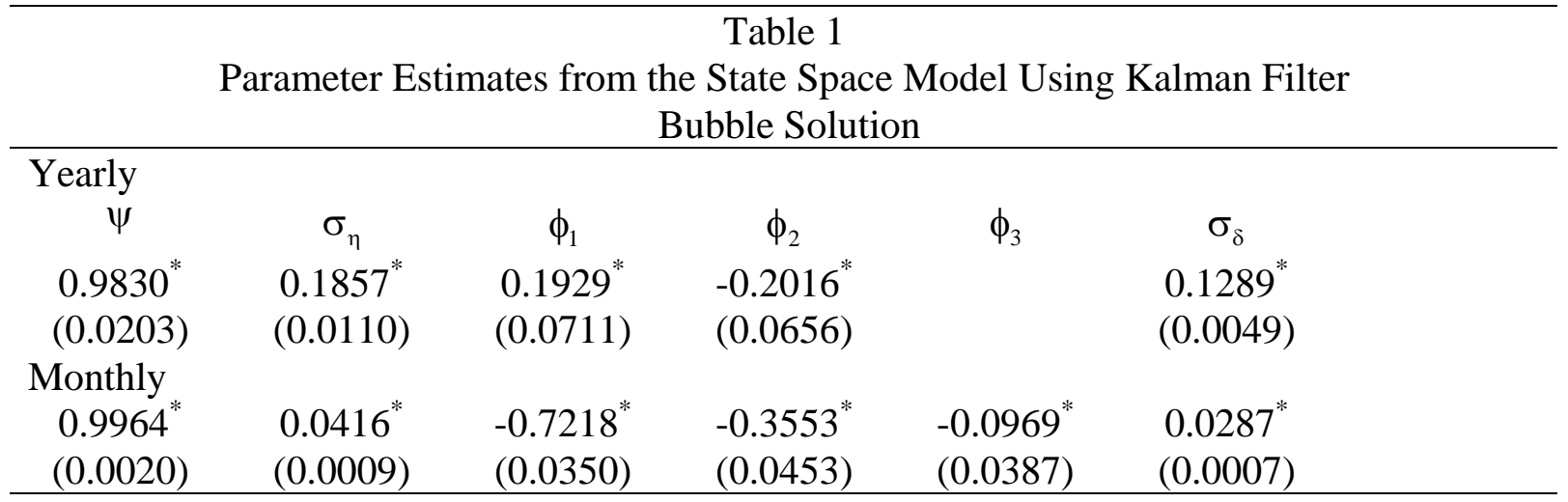

Estimates reported here are obtained from maximising the innovation form of the likelihood function. Numerical optimisation procedure in GAUSS is used without any parameter restriction. The standard errors (reported below the parameters in parentheses) are obtained from the Hessian matrix at the point of convergence. These estimates are robust to different starting values including different specification of the prior covariance matrix. Significance at $5 \%$ level is indicated by *

Table 2

Parameter Estimates from the State Space Model Using Kalman Filter No Bubble Solution with GARCH(1,1) Error for Price Equation

Yearly 


\begin{tabular}{cccccccc}
$\psi$ & $\phi_{1}$ & $\phi_{2}$ & $\phi_{3}$ & $\sigma_{\delta}$ & $\alpha_{0}$ & $\alpha_{1}$ & $\beta_{1}$ \\
$0.6195^{*}$ & $0.2170^{*}$ & $-0.2164^{*}$ & & $0.1290^{*}$ & 0.0073 & 0.1754 & $0.6054^{*}$ \\
$(0.1327)$ & $(0.0867)$ & $(0.0856)$ & & $(0.0081)$ & $(0.0062)$ & $(0.1279)$ & $(0.2649)$ \\
& & & & & & & \\
Monthly & & & & & & & \\
$0.3189^{*}$ & $-0.7213^{*}$ & $-0.3271^{*}$ & $-0.0901^{*}$ & $0.0288^{*}$ & $0.0001^{*}$ & $0.0657^{*}$ & $0.8365^{*}$ \\
$(0.0344)$ & $(0.0413)$ & $(0.0484)$ & $(0.0400)$ & $(0.0008)$ & $(4.62 \mathrm{e}-5)$ & $(0.0274)$ & $(0.0533)$ \\
\hline
\end{tabular}

Estimates reported here are obtained from maximising the innovation form of the likelihood function. Numerical optimisation procedure in GAUSS is used without any parameter restriction. The standard errors (reported below the parameters in parentheses) are obtained from the Hessian matrix at the point of convergence. These estimates are robust to different starting values including different specification of the prior covariance matrix. GARCH(1,1) error for state space system implemented following Harvey, Ruiz, Sentana (1992). Significance at 5\% level is indicated by *.

\begin{tabular}{cccccc}
\hline \multicolumn{5}{c}{ Table 3 } \\
Residual Diagnostics and Model Adequacy Tests \\
Yearly & Portmanteau & ARCH & KS Test & MNR & Recursive T \\
Bubble & 0.035 & 0.385 & 0.138 & 0.531 & 0.952 \\
No Bubble & 0.033 & 0.519 & 0.119 & 0.422 & 0.931 \\
& & & & & \\
Monthly & & & & & \\
Bubble & 0.377 & 0.327 & 0.048 & 0.425 & 0.894 \\
No Bubble & 0.353 & 0.283 & 0.047 & 0.418 & 0.846 \\
& & & & & \\
\hline
\end{tabular}

Entries are p-values for the respective statistics except for the KS statistic. These diagnostics are computed from the recursive residual of the measurement equation, which corresponds to the real dividend process. The null hypothesis in portmanteau test is that the residuals are serially uncorrelated. The ARCH test checks for no serial correlations in the squared residual up to lag 26. Both these test are applicable to recursive residuals as explained in Wells (1996, page 27). MNR is the modified Von Neumann ratio test using recursive residual for model adequacy (see Harvey (1990, chapter 5). Similarly, if the model is correctly specified then Recursive T has a Student's t-distribution (see Harvey (1990, page 157). KS statistic represents the Kolmogorov-Smirnov test statistic for normality. 95\% and 99\% significance levels in this test are 0.121 and 0.145 respectively for annual data. When KS statistic is less than 0.121 or 0.145 the null hypothesis of normality cannot be rejected at the indicated level of significance. For the monthly data these significance levels are at 0.057 and 0.068 respectively. 


\section{Table 4}

Bubble Solution Versus No Bubble with GARCH Error Compared

\begin{tabular}{|c|c|c|}
\hline & RMSE & MAE \\
\hline \multicolumn{3}{|l|}{ Yearly } \\
\hline Bubble & 0.25 & 0.34 \\
\hline No Bubble GARCH $(1,1)$ & 1.37 & 1.42 \\
\hline \multicolumn{3}{|l|}{ Monthly } \\
\hline Bubble & 0.117 & 0.895 \\
\hline No Bubble GARCH $(1,1)$ & 1.734 & 1.735 \\
\hline
\end{tabular}

RMSE and MAE stand for 'root mean squared error' and 'mean absolute error' respectively. These are computed from the differences between the actual log prices and the fitted log prices from the corresponding estimated model. Additional details are in the text.

Figure 1

Plots using the Smoothed Estimates of the Bubble from the State Space Model Yearly Data

Bubble/Price Ratio (\%): Yearly US Data

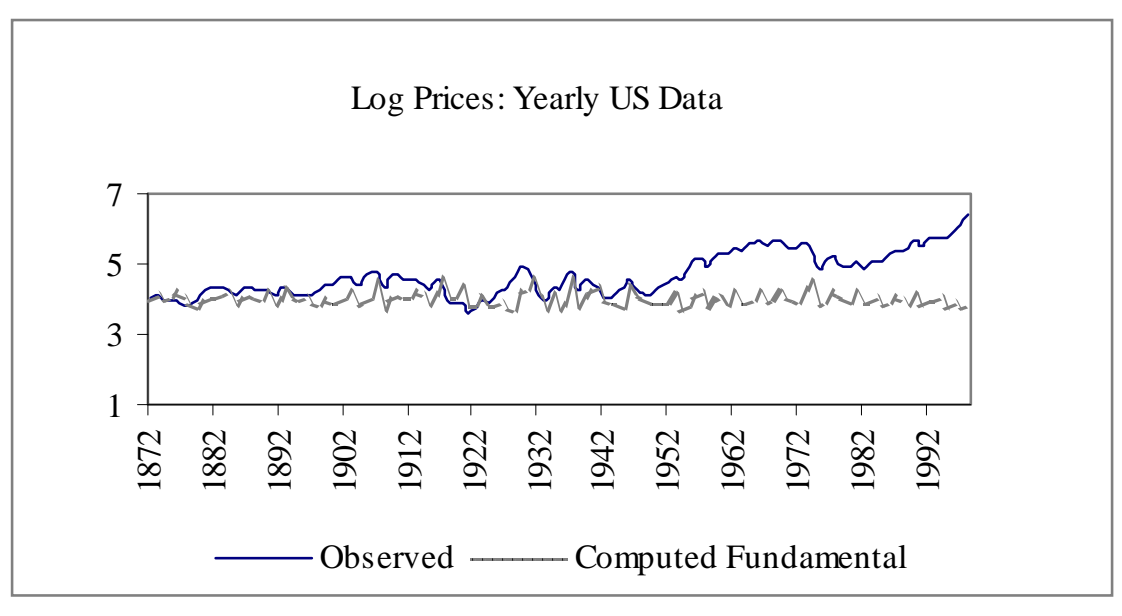


Figure 2

Plots using the Smoothed Estimates of the Bubble from the State Space Model Monthly Data

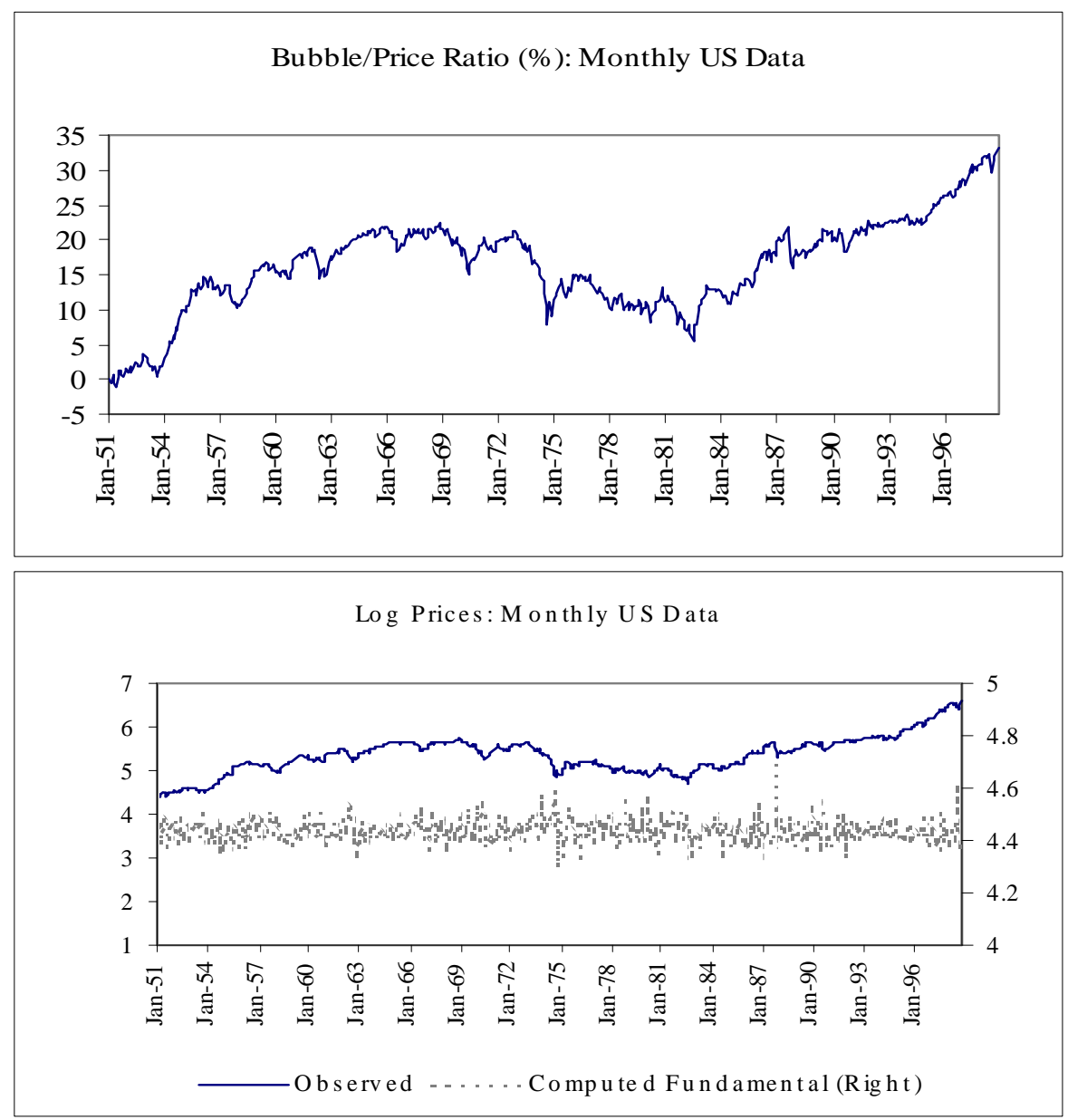

